\title{
The Role of Universities in International Response to Pandemic Threats
}

\author{
David W. Chapman ${ }^{1} \&$ Kaylee Myhre Errecaborde ${ }^{2}$ \\ ${ }^{1}$ College of Education and Human Development, Univesity of Minnesota, Minneapolis, Minnesota, United States \\ ${ }^{2}$ College of Veterinary Medicine, University of Minnesota, St. Paul, Minnesota, United States \\ Correspondence: David W. Chapman, College of Education and Human Development, Univesity of Minnesota, \\ Minneapolis, Minnesota, United States. Tel: 1-612-626-8728. E-mail: chapm026@umn.edu
}

Received: June 30, 2016

Accepted: July 11, 2016

Online Published: September 6, 2016

doi:10.5539/hes.v6n4p12

URL: http://dx.doi.org/10.5539/hes.v6n4p12

\begin{abstract}
Faced with increasing pressure to generate more of their own budgets, universities in low and middle income countries are increasingly banding together as country and regional-level networks to bid on and subsequently implement externally funded development projects (a pattern already seen in high income countries). While working as a network may offer a competitive advantage in bidding on international contracts, it also introduces a new set of dynamics in cross border collaboration among higher education institutions. This paper examines the dynamics of university networks, drawing on the experience of one regional and four country-level networks in South East Asia which were created to promote better national preparation and response to pandemic threats. Findings suggest that, in many universities, university efforts to work through networks is a source of considerable controversy as it pushes institutions and individuals into new roles and often conflicts with existing institution-level incentive systems.
\end{abstract}

Keywords: university networks, higher education, Southeast Asia, global health security, pandemic threats

\section{Introduction}

\subsection{Introduction to the Problem}

The Ebola outbreak has not only focused world attention on the humanitarian and economic threat posed by epidemics, but also on the importance of having a workforce capable of preventing or quickly containing infectious disease outbreaks. Indeed, some argue that the best predictor of a low incidence of epidemic outbreak and of the ability of a country to contain such outbreaks is the preparation and competence of its health-related workforce (Deen, 2015). A "One Health" approach, which acknowledges that the health of humans, animals, and the environment is inextricably linked and emphasizes an interdisciplinary approach to health workforce training, is seen as paramount to building preparedness for emerging infectious disease threats. Recognizing this, development organizations (e.g., "donors") are putting substantial resources into improving the training for health profesisonals who need to work across animal and human health sectors in countries identified as potential "hot spots" for emerging pandemic disease (Jones, 2011).

One strategy for improving the health-related workforce is to work through universities in target countries to improve the quality, relevance, and delivery of pre-service (training for pre-graduate students) and in-service (training for post-graduate working professionals) of health-related academic programs. Universities are well positioned to transform how infectious disease threats are managed globally since nearly all health workers in at-risk countries are trained through local or national universities. In addition, universities are historically among the most stable institutions in insecure regions of the world, often withstanding social and political disruption and remaining as institutions of knowledge and training for the future. However, recent research on the operation of university networks has found that their success in promoting better instruction is sometimes constrained by the "politics" of network operations (Chapman, Pekol, \& Wilson, 2014). Networks can face conflicting interests related to leadership, agenda setting, and funding flows. A fuller understanding of these dynamics is important to donor efforts seeking to work through university networks in strengthening national disease response systems. 
This paper draws on current data from one regional and four country-level networks in South East Asia to examine the dynamics of country-level university networks as a mechanism for promoting better national preparation and response to the threat posed by emerging infectious disease.

\subsection{Relevant Background}

Initiatives aimed at strengthening countries' disease response capabilities are frequently funded, all or in part, by international development organizations, running the risk that component activities end when the money ends. Some observers have suggested that anchoring such development initiatives in higher education institutions can promote sustainability since higher education institutions typically have credibility within their own countries and often have longevity outlasting changes in national governments. However, this has been controversial as, in many countries, universities and central governments have historically had an uneasy relationship (Chapman \& Claffey, 1998). Academic faculty may see engaging in outreach activities as beneath their station and these activities may not align with criteria for promotion and tenure. On the other hand, governments may see university involvement in workforce planning and assessment as encroachment on government prerogatives. Despite these concerns, the lure of donor funding is powerful, both to recipient governments concerned about their ability to address pandemic threats and to higher education institutions in countries that are under-funded.

Over the last five years, four countries in South East Asia (Indonesia, Malaysia, Thailand, and Vietnam) have been successful in establishing country-level networks for the purpose of strengthening the preparation of future animal and health care workers. This is not to say that the organization and operation of these networks have not faced challenges. Earlier research by Wilson (2012) and Chapman, Pekol and Wilson (2015) have found that the dynamics of university collaboration are shaped and often constrained by differing, and sometimes conflicting, incentive systems that function at different levels of network operation. The challenge is magnified when actors at each level fail to fully understand the dynamics shaping the behavior of actors at the other levels. This study extends the earlier work by Chapman et al. (2015). Their study focused on university networks funded by USAID under its RESPOND project, which operated from 2009-2014. Following the conclusion of RESPOND, USAID launched the One Health Workforce (OHW) project to continue support and organizational development of those networks over an additional five year period from 2014-2019. The present study was conducted within the OHW project in South East Asia. A brief description of this network is necessary as the basis for the subsequent discussion.

\subsubsection{The Regional One Health University Network in Asia}

The South East Asia One Health University Network (SEAOHUN) was founded in 2011 with funding from the USAID RESPOND project. It operates as a regional network with membership including 14 faculties of medicine, veterinary medicine, public health and nursing from 10 universities in Indonesia, Malaysia, Thailand and Vietnam. The network is associated with two universities in the United States (the University of Minnesota and Tufts University) which serve as conduits for the USAID funding and provide technical support and assistance through the current USAID One Health Workforce project. The long term goal of SEAOHUN is to train a workforce capable of using the One Health approach to build trans-disciplinary capacity across South Eeast Asia to respond to emerging infectious diseases. Management of the network rests with a regional secretariat located in Chiang Mai, Thailand governed by a Foundation Board and Executive Board composed of representatives of the member universities from Indonesia, Malaysia, Thailand, and Vietnam, the four counties that together founded the regional network. The primary activities of the regional network are to serve as an administrative agent for the USAID funds, coordinate planning of the regional and country level networks, sponsor region-wide activities in support OHW goals and, over time, seek additional funding from a wider circle of external donors.

\subsubsection{The Country-Level Networks}

Following the inception of SEAOHUN, the university members sought a way to engage a wider set of universities in project activities. To that end, member universities of the regional network took responsibility for leading the development of country-level networks in their respective countries. The country-level networks are administrated through a National Coordinating Office (NCO) and activities are implemented through a core member institution. Each country-level network receives a sub-allocation of USAID funds from USAID through the prime contractor, the University of Minnesota (discussed below). Funds are anticipated to eventually be routed through the SEAOHUN Secretariat. These country networks then work directly with their university members to engage faculty in annually planned project-related to health workforce development activities. 


\subsubsection{The OHW Contractor}

To implement its projects, USAID generally utilizes outside organizations selected through a competitive bidding process. In the case of OHW, the University of Minnesota (UMN) was selected as the prime contractor working in collaboration with Tufts University as a subcontractor. UMN's role is to administer the funds from USAID, assist networks to develop annual work plans consistent with USAID priorities and OHW project objectives, distribute project funds to the networks, provide technical assistance and support the networks in activity implementation as needed, monitor and document implementation of the annual work plans, and provide USAID with a variety of reports on project activities and expenditures.

\subsubsection{The Network Member Universities and Their Faculty Members}

Ultimately, it is faculty members in member universities who design and deliver the intended instruction. Engaging faculty in the service of the larger project requires that project leadership at USAID, UMN, Tufts, and network personnel understand the incentive systems for member institution faculty and how their engagement in the project aligns with their university's priorities and their own promotion and tenure within that institution.

\subsection{Conceptual Framework and Relevant Scholarship}

The international literature on cross-border networks in higher education have consistently argued that the success of cross-border collaboration in higher education depends on the actions of multiple stakeholders, but that these stakeholders often vary in the outcomes of the collaboration they regard as most important (Sakamoto \& Chapman, 2010; Chapman, Cummings, \& Postiglione, 2010). Success of cross-border collaborations do not necessarily require that partners share the same goals, as long as they understand each other's motivations and as long as the goals of all partners can be achieved. However, these conditions are not always met. These studies have found that partners in university collaboration often fail to understand the dynamics that underlay the decisions of other partners, leading to confusion and tension. This study posits that a similar dynamic operates in how the different levels of a university network operate. Actors at different levels may not fully understand or necessarily support the actions of those at other levels of the network. They may not see collaboration as being in their personal best interest. In short, actors at each level of the network may be responding to different incentive systems.

Figure 1 provides an overview of the main players in the OHW project and how they interact. As the later discussion will highlight, while these groups must work together for the network to be successful, each group must also respond to a set of pressures unique to their role and, in doing so, each is driven by a different set of incentives. The circle within the USAID circle represents UMN in the role to administer project funds and support technical and organizational development. In addition, the small circle at the center of the Venn diagram represents the "window" where objectives and incentives align for successful activity planning and implementation among the different layers of management from USAID to the individual faculty. When the different incentive systems get too far out of alignment, the working relationships among groups can come under considerable stress. 


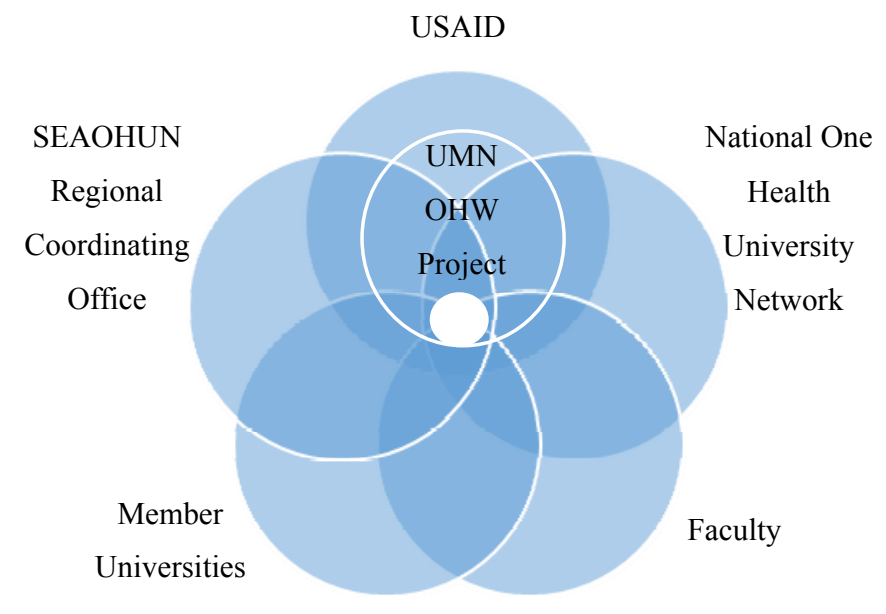

Figure 1. Venn diagram of groups involved in network support and operation. Each circle represents individual incentives and the overlap illustrates the marginal areas where incentives may align for the multiple entities involved in network management and operation

In the context of the SEAOHUN network, the authors posit that university collaboration depends on actions within and interactions among, six key groups: (1) USAID as the donor organization funding the network, (2) UMN as the contractor who administers the funds for USAID and provides organizational development and technical support to the networks, (3) SEAOHUN as the regional network organization, (4) each country-level university network, (5) the individual member institutions, (6) their faculty members who ultimately, play the major role in implementing networks activities and training the workforce.

This study was grounded in Lane and Kivito's (2008) work on principal-agent theory as it operates in higher education. This theory addresses the dilemma of how individuals at one level of an organizational system can operate to get individuals at a different level of the system to act in desired ways. The theory posits that this is accomplished through the application of incentives in combination with an accountability system to ensure that incentives only go to those who deserve them (Lane \& Kivito, 2008; Wan et al., 2016). In a hierarchical organization, one approach is for administrators to rely on their organizational power and authority as the basis for getting staff to operate in the desired ways. However, as Lane and Kivito (2008) point out, in universities academic faculty have a certain level of autonomy that comes from expertise and the specialized nature of academic work. Faculty members may operate from self-interest rather than the interest of network or university administrators. The goals of the principal and the agent may not always coincide. The agent is expected to operate in the best interest of the principal but the agent may be diverted from doing so by self-interest. In the academic setting then, getting agents to pursue desired ends requires that the principal provide incentives and monitor agent behavior to ensure that the principal's interests are indeed accomplished.

Thestudy also draws on incentive theory (Bernstein, 2011; Explorable, 2015) which posits that the behavior of individuals and organizations is primarily extrinsically motivated. Organizations and individuals are more motivated to undertake activities if they receive a reward for doing so, rather than simply because they enjoy the activities themselves (see also Olson, 1971). The premise of this study is that individuals at each level of the network framework must see the network activities in which they are involved as promoting ends which they value and which advance their own career. Network success depends on partners finding ways to expand the areas of intersection. 


\section{Methods}

This study is framed as a vertical case study (Vavrus \& Bartlett, 2009) which seeks to situate actions at each level of an organization within the cultural, political, and fiscal context of the larger system in which they are a part. It seeks to clarify how actions at one level shape and influence actions at other levels of the system. The present study examined how actors at six levels of network organization respond to the opportunities posed by the creation of a regional network aimed at improving pre-service university instruction in health related fields and how those at each level interact with those at the other levels of network organization.

This paper draws on data collected through interviews conducted during site visits to the country-level university networks in Indonesia, Malaysia, Thailand, and Vietnam (described above). Interviews were scheduled through email correspondence between the researcher and each network's National Coordinating Office (NCO). The $\mathrm{NCO}$ arranged for staff participation in the interviews. Interviews were conducted at the respective network offices and, in every case, interviewees included the NCO Coordinator (Director of the network), deputy coordinator (where such a role existed), and staff members responsible for technical implementation, monitoring and evaluation, communications, program development, and financial accounting. Interviews were conducted through a combination of individual and group interviews to accommodate the ongoing work flow in the offices.

The interviews collected data on the substantive activities these networks were undertaking and the political, operational, and financial issues they were encountering in doing so. More specifically, the interview protocol covered eight thematic topics which are summarized in Figure 2. The interview protocol was shared with each NCO coordinator 1-2 weeks in advance of the country visits to promote thoughtful preparation for the interview. A total of 29 semi-structured interviews were conducted with network staff, as summarized in Figure 3. Data has been summarized around key themes that emerged in the interviews.

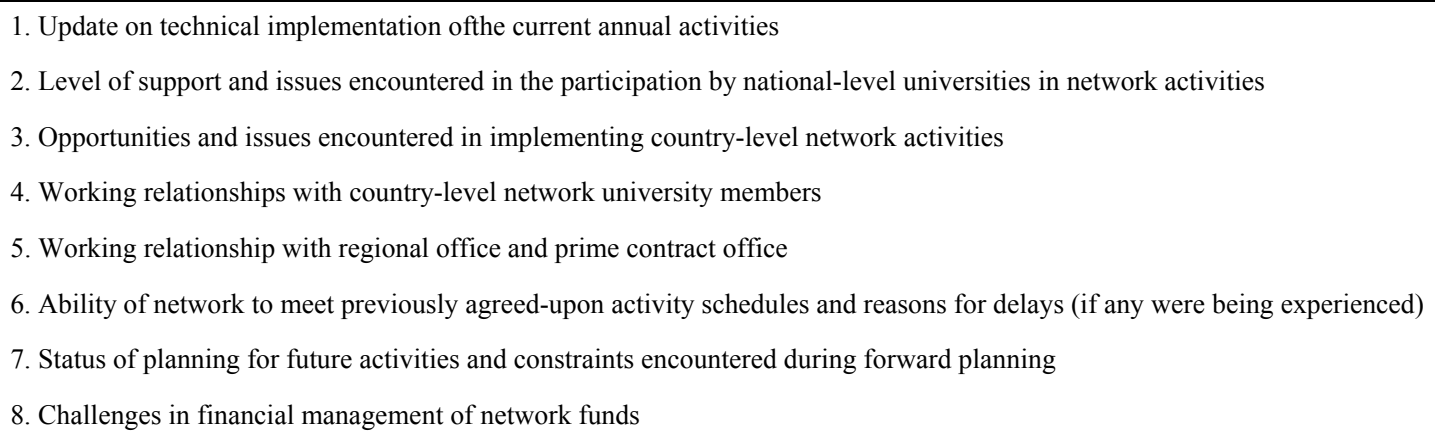

Figure 2. Protocol used in Interviews with Country Level Networks

\begin{tabular}{|l|c|}
\hline \multicolumn{1}{|c|}{ Network } & N \\
\hline Malaysia One Health University Network & 8 \\
\hline Vietnam One Health University Network & 8 \\
\hline Thailand One Health University Network & 7 \\
\hline Indonesia One Health University Network & 6 \\
\hline Total & 29 \\
\hline
\end{tabular}

Figure 3. Number of interviews conducted by Network

\section{Results}

At the time this study was undertaken, the regional and country university networks had already been established and were operational. However, interviews indicated that the prospect of substantial new funds being available for continued work to improve the quality and delivery of pre-service health-related academic programs sparked interest and galvanized attention of universities and their respective academic staff. The networks provided a mechanism through which those funds could flow and established a set of procedures though which universities could access those funds. At the same time, issues arose that illustrate some of the complexities of cross-border and multi-institutional collaboration in higher education 


\subsection{USAID}

When USAID funded OHW they specified five overarching objectives (Figure 4). Soon after the funding was approved, it was indicated that not all objectives should receive the same attention. This prioritization of objectives was primarily in response to two factors. First, at the time USAID funded OHW, they also funded two other international projects with partially overlapping mandates. To better coordinate these projects, USAID directed OHW to narrow the focus of its work to prioritize project objective 2 and focus almost exclusively on working with universities to improve the quality, relevance, and delivery of pre-service health-related academic programs, and for the time being, leave project objective 1 and 3, work with government disease response systems and in-service education to other organizations. At about the same time, with the rise of the Ebola epidemic, USAID received additional new U.S. government funding to assist high-risk countries to improve their disease response systems.

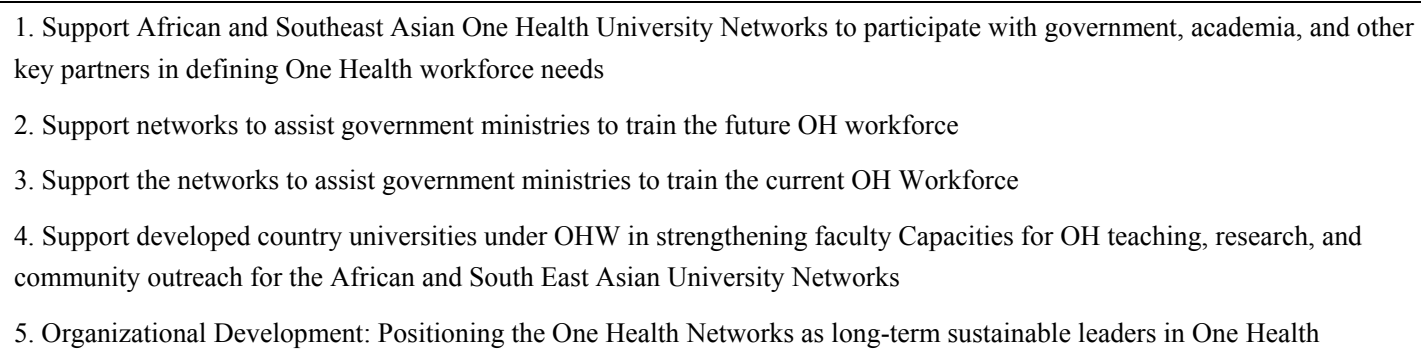

Figure 4. USAID specified one health workforce objectives

Given the urgency of the situation and the complexities of government contracting, USAID distributed the new money through existing contracts. Consequently, funding for OHW increased from $\$ 7.86$ million in year 1 to $\$ 15.86$ million in year 2, with the expectation, though no guarantee, that the higher funding level would continue in subsequent years. USAID indicated that the funding needed to be spent in the year for which it was allocated. The cumulative effect of narrowing the scope of allowable project activities under OHW while substantially increasing the funding put considerable pressure on the contractor, the networks, and member universities to identify ways to effectively use large amounts of money in a short time.

\subsection{Contractors}

UMN was responsible for quality control of activities and the administration of network expenditures. This often involved balancing competing interests. USAID expected the contractor to ensure that network activities addressed USAID priorities, field activities were moving forward on schedule, and intended project outcomes were being achieved. Network personnel believed they better understood national needs and local priorities and chafed at having an outside group exercise oversight of their decisions. To be successful, UMN needed to build a cordial and effective working relationship with the network personnel while also enforcing USAID priorities and rules. This was sometimes a challenge since USAID priorities were not always well aligned with those of member universities (discussed below). This situation was made more complex by skepticism among network and member university personnel about whether USAID funding would continue at the elevated level. This distrust stemmed, in large part, from an abrupt, premature de-obligation of network funds that networks experienced during the waning days of the earlier USAID RESPOND project. As such, member universities were reluctant to engage in activities that involved multi-year financial commitments, fearing funds might again stop mid-steam or further change implementation priorities that would leave them financially exposed. Consequently, this limited the scope and strategy of many of the activities the networks proposed.

\subsection{SEAOHUN}

Regional university networks, to survive, must demonstrate that they are providing services or products to member networks and institutions that those members cannot, or chose not to, provide for themselves. Networks are typically only the instigator of regional activities and the conduit of funds. They rely on faculty at member institutions to undertake the substantive work associated with improving university curriculum and instruction in ways that align with network goals. The real work of the networks occurs at the level of individual universities. This exposes a dilemma for the network. If network success depends on the work conducted within member institutions, administrators of those member universities may regard the funds going to support the network 
infrastructure as unnecessary bureaucracy and push to have the funds come directly to their institutions. Networks may be seen as competitors or unnecessary middleman by member institutions. This dynamic gave rise to a series of issues.

\subsubsection{Organizational Instability}

In the case of SEAOHUN, this view (questioning the value of the regional network) gained strength due to internal organizational issues within the regional network itself. The administrative structure of SEAOHUN, established under the RESPOND project, was supposed to carry forward into the new project. Funds were to flow from USAID, through the contractor, to SEAOHUN, then to the country-level networks, and eventually to the member universities. However, within the first two months of the start of the OHW project, the regional manager of SEAOHUN chose to not renew the contracts of the two administrative staff and then, in a disagreement with the Chair of the SEAOHUN Executive Board, resigned with little warning. This left the regional network without an administrative staff just as OHW project activities were scheduled to begin. While the Executive Board eventually hired a new regional manager and supporting staff members, it took several months and, once hired, the new staff needed training in USAID and contractors regulations and procedures.

To allow project activities to move forward in the interim period, the contractor decided to channel project funds earmarked for the country networks directly to those networks. The plan was to shift responsibility for allocation of county level funds to the newly reformed SEAOHUN staff once they were trained and administrative systems were in place. In the short term, however, this arrangement shifted more responsibility to the country networks for activity planning and budget management and weakened the regional network role in the project. The country-level networks to date have proved to be competent and capable in the role of administrators and technical experts. This development, then, begs the question of what value-added is provided by a regional secretariat? If the regional staff are not technical experts in the development and delivery of instruction and the country level networks are capable of handling the flow of project funds, a regional layer of administration may not be efficient or necessary.

\subsection{Country Level Networks}

It fell to the country networks to engage their member universities in planning the specific activities that would lead to more relevant and interdisciplinary curriculum and instruction. Network staff were quickly faced with several dilemmas:

\subsubsection{Mixed Messages}

An immediate issue that faced each network was whether funds should be allocated to the strongest universities in the country which had the staff and experience to spend the money quickly, or should the money be spread across a wider range set of universities in order to more broadly strengthen pre-service university preparation of health care workers throughout the country? USAID was clear in wanting the money spread across many universities across each country. But USAID was also clear that it wanted the money spent quickly and well. Networks were getting mixed messages. To spend funds quickly, networks tended to favor strong university members, those able to quickly propose and deliver on activities. This raised the ire of some USAID personnel that expected to see the funds more widely shared. This also created some problems with national ministries who expressed concern over which universities were receiving funds, and the extent that these funds were provoking changes in programs that needed ministry approval.

\subsection{Member Universities}

Universities join networks to be a part of a larger movement that will bring them recognition and to address a national priority. Nonetheless, the expectation of new resources is a major lure. While 2-3 universities in each member country hold membership in the SEAOHUN regional network, most universities are only members of the national university network. At the country level, member universities meet at least annually to identify possible activities to be undertaken with project funds and the role individual universities wish to play in those activities. If universities join and resources flow, students can benefit from improved instruction. If universities join but resources do not the flow, university personnel may lose interest and fall away. The root issue for universities is whether the involvement of their faculty in network activities furthers the interest of the institution.

\subsubsection{Conflicting Incentives Systems}

These networks were funded with the explicit goal of improving university-based instruction in health related disciplines. A priority activity was to develop and or upgrade instructional curricula, courses, and pedagogical practices aimed at improving the academic preparation of future health workers. However, interviewees across 
all four networks said they were having difficulty getting academic staff interested and engaged in such activities. The reasons for this lack of interest traces back, in large part, to the internal reward structure of universities in these countries. While there are differences among countries, most member universities in all four networks assigned high value to raising their standing in national and international university ranking systems.

The motivation of university officials is more than institutional pride. In some countries, such as Malaysia and Thailand, some portion of government financial support of these universities is based on their ability to sustain or raise their standing in these international rankings (UNESCO Institute of Statistics, 2014). The fastest way for a university to raise its rankings is to increase research and publication rates among academic staff. Consequently, university reward systems are heavily oriented toward faculty members' research productivity as indicated by their publication rate. While these universities value good teaching, they tend to reward faculty on the basis of publication in international journals. This poses a challenge for networks that are focused on developing and upgrading curriculum, instructional materials and pedagogical practice. Administrators in all four networks observed that faculty members were caught between their university's focus on raising university rankings through increased research and publication and the networks' emphasis on improving instruction. Project incentives were at odds with the incentive structures of the faculty members' own institutions, and ultimately, didn't support individual faculty career progression within their own academic institutions.

\subsubsection{Procedures at Cross-purposes}

In responding to the dilemma of misaligned incentives, network managers argued that offering financial incentives to faculty to develop or redesign courses would be an effective means of engaging faculty in network activities. This posed an additional dilemma. USAID rules do not allow project funds to be used to pay foreign government employees to do work that is considered to be a part of their regular government job. Since most of the member universities are public universities, academic staff are government employees and paying them would be considered "double-dipping". In some countries, such as Indonesia, faculty are paid somewhat lower wages with the expectation that they will receive supplemental compensation for each activity in which they engage. So, for example, a faculty member might receive additional pay to attend a meeting or serve on a committee. From the perspective of network administrators, not providing faculty with additional compensation for work on network activities signals a lack of cultural awareness.

\subsubsection{The Pain of Sharing}

As described earlier, since country network offices did not have financial management systems that would meet USAID auditing standards, a well-established university in each country served as the host for the country network administrative office and served as fiscal agents for that network. This created an issue in at least two countries when, once resources were received, the university business offices were reluctant to release the funds to other universities, arguing that the work should be undertaken by faulty from their own institution. This created conflict between member institutions in the network making them feel as though they were in competition with each other and, to some extent, caused conflict and competition between network managers and their own university administrators. The situation led to delays and distortions in getting the funds distributed to member universities and accomplishing project activities.

\subsubsection{Pay for Effort or Pay for Output}

Faculty wanted to be paid for developing instructional modules but not necessarily for teaching them. This allowed them to get paid for developing course material without the complexities of having to integrate the materials into programs and courses that were already over-packed with content. While course development could be undertaken as an individual activity, teaching those courses generally involved modifications to the established and approved curriculum which, in turn, entailed negotiations with colleagues and administrators. The potential conflict involved in pursuing these changes and "political" cost of such negotiations were off-putting to many faculty members. Eager to spend funds quickly, attaching the payments to materials development had some appeal to the network administrators. Money could be spent relatively quickly, since instructional modules could be accomplished within a year, while actually teaching those modules often flowed into a subsequent years. Many of the networks are now moving to integrate materials that were developed early on in the project into the class room to actually change training for students. This has supported multi-year initiatives that are not necessarily tied to annual funding.

\subsubsection{Focus Effort or Distribute Effort}

While modules were easier to integrate into the instructional program, the focus on developing instructional modules meant that network administrators had to initiate and manage many smaller activities rather than fewer 
large initiatives. This increased the administrative burden on the network offices and, in some cases, stressed the capacity of the country network office to monitor and manage activities. Moreover, while adding complexity, the focus on module development did not spend funds as quickly as larger course development efforts. The overall impact was more complexity combined with a lower spend-rate.

\subsection{University Faculty}

Network activities ultimately depend on the work of individual faculty members. Consequently, the benefit flow needs to reach to the level of these individuals. Networks will only succeed to the extent that they can capture the interest and motivation of the instructional staff at the member universities. As the preceding discussion has indicated, faculty are often caught in the middle of misaligned and sometimes conflicting message and offered only weak incentives.

\section{Discussion}

Principal-agent theory, in which this study was framed, posits that managers at each level of SEAOHUN motivate those at lower levels of the network to act in desired ways through the application of incentives within an accountability system that ensures incentives go to those who deserve them (Lane \& Kivito, 2008; Wan et al., 2016). Since its inception, SEAOHUN has had the structure of a hierarchical organization, though university member affiliation with the network has always been voluntary. Network coodinators have little recourse to influence organizational power or authority and as such, have little control to incentivize staff or university member faculty to operate in desired ways. The primary tool to shape behavior is the control of financial resources and the flow of those resources to lower levels of the network. Frequently, managers at higher levels of the network have been preoccupied with being responsive to donor guidance and administrative requirements and thus failed to fully comprehend the competing pressures of those at lower levels, pressures that often tempered the motivational value of the funding. Moreover, the network lacked a meaningful accountability system. The pressure from USAID to ensure rapid utilization of the money resulted in managers giving less attention to outputs and outcomes as a basis for continued funding. Managers could compete for funds with little concern that non-performance would have serious financial consequences. This study illustrates how key actors at each level may understand and subscribe to network goals and activities yet believe they are constrained by their own organization's rules from operating in ways that lead to effective cross-institutional cooperation. Incentive systems were in conflict.

While current findings are consistent with earlier research on the dynamics that can arise in the operation of multi-level university networks, they provide additional insight into the source of such tensions. International literature posits that network success is constrained when different stakeholders do not fully understand the incentives influencing the behavior of other groups (Sakamoto \& Chapman, 2010). Findings of this study suggest that the multitude of stakeholders across university networks often do understand the motivations and incentives of other groups and that tensions are sparked when these incentives systems do not align and when each actor naturally prioritizes their own organizational and personal interests.

These misalignments undercut goal attainment. Among other things, the networks were grappling with (a) shifting donor priorities; (b) misalignment of faculty incentive systems and network objectives; (c) conflict between standard compensation practices of member universities and USAID rules; and (d) resistance to resource sharing within some networks.

The pressures on USAID to spend funds in the year in which they are received was conveyed downward, through the network structure, without a full understanding within USAID of how the consequences of that pressure at the country network and university level. These pressures shaped the decisions of network administrators who sought to balance the urgency to spend with the need to produce meaningful outcomes. In the end, the pressure to spend was immediate, while outcomes were in the future. Incentives were attached more closely to process considerations than to outcome considerations.

Outcomes important to USAID (spending funds in a given time frame) were misaligned with the realities of how curriculum and instruction actually gets developed at universities. Incentive systems of USAID, universities, and academic staff clashed in ways that undercut the effectiveness of network goal achievement. At the same time, actors within the regional and national networks often failed to understand the nature or significance of these misalignments. Even if they came to understand them, they were often unable to modify their organizational behavior to adjust to or resolve the differences, since the differences were held in place by larger incentive systems. 
The SEAOHUN Secretariat experience highlights the risks a top-down strategy to improve university instruction, particularly when that strategy involves creating multiple administrative layers. One issue arising in the case of SEAOHUN has been the instability of a free-standing regional network. The regional-level network was created and sustained by external, donor funds and operated outside of any specific university framework. This left it particularly vulnerable to shifts in personnel turnover and funding flows. Moreover, this vulnerability forced the country-level networks to function independent of the regional secretariat, and as such have become confident independent entities both administratively and technically. In the SEAOHUN experience, this dynamic led some participants to question the need for a regional level organization.

The experience of SEAOHUN as a regional network highlights issues that may be relevant to the design of other cross border university networks.

\section{References}

Bernstein, D. A. (2011). Essentials of psychology. Belmont, CA: Wadsworth.

Chapman, D. W., \& Claffey, J. (1998, September 11). Higher Education and International Development: Some New Opportunities Worth Taking, Point of View commentary, Chronicle of Higher Education (Vol 5, p. B6).

Chapman, D. W., Cummings, W., \& Postiglione, G. (Eds.). (2010). Crossing Borders in East Asia Higher Education. New York: Springer Publishing.

Chapman, D. W., Pekol, A., \& Wilson, E. (2014). Cross-border university networks as a development strategy: Lessons from three networks. International Review of Education. Retrieved from http://link.springer.com/article/10.1007/s11159-014-9439-8.

Deen, J. (n.d.). Personal communication.

Explorable. (2015). Incentive Theory of Motivation. Retrieved December 10, 2015, from https://explorable.com/incentive-theory-of-motivation

Jones, K. (2011). Global trends in emerging infectious diseases. Nature, 451, 990-993. http://dx.doi.org/10.1038/nature06536

Lane, J. E., \& Kivisto, J. A. (2008). Interests, information, and incentives in higher education: Principal-agent theory and its potential applications to the study of higher education governance. In J. Smart (Ed.), Handbook of Theory and Research (pp. 141-179). Rotterdam: Springer.

Olson, M. (1971). The logic of collective action: Public goods and the theory of groups. Cambridge, MA: Harvard University Press.

One Health Workforce. (2014, November 1). Retrieved December 28, 2015, from https://www.usaid.gov/sites/default/files/documents/1864/one-health-workforce-factsheet.pdf

Sakamoto, R., \& Chapman, D. W. (2010). Cross-Border Partnerships in Higher Education: Strategies and Issues. New York: Routledge.

SEAOUHN Foundation Bi-Laws. (2015, July 7). Retrived December 29, 2015.

UNESCO Institute for Statistics. (2014). Higher Education in East and Southeast Asia: Expand Out, Expanding $U p$. Montreal: UNESCO Institute of Statistics.

Vavrus, F., \& Bartlett, L. (2009). Critical Approaches to Comparative Education: Vertical Case Studies from Africa, Europe, the Middle East, and the Americas. Palgrave MacMillan: New York. http://dx.doi.org/10.1057/9780230101760

Wan, C. D., Chapman, D., Hutcheson, S., Lee, M., Austin, A., \& Md. Zain, A., (2016). Changing higher education practice in Malaysia: The conundrum of incentives, Studies in Higher Education. http://dx.doi.org/10.1080/03075079.2015.1134475

Wilson, E. (2012). Faculty perceptions of success in cross-border university-to-university partnerships (Unpublished Ph.D). Department of Organizational Leadership, Policy and Development, Minneapolis: University of Minnesota. 


\section{Copyrights}

Copyright for this article is retained by the author(s), with first publication rights granted to the journal.

This is an open-access article distributed under the terms and conditions of the Creative Commons Attribution license (http://creativecommons.org/licenses/by/4.0/). 